\title{
Haemorrhage as a Complication of Extracorporeal Pig Liver Perfusion: Studies on Mechanism and Prevention
}

\author{
JOHN WINCH， J. KOLTHAMMER， R. HAGUE,
}

British Medical fournal, 1972, 2, 735-738

\section{Summary}

The use of extracorporeal pig liver perfusion for temporary liver support has been followed not infrequently by major bleeding with a fall in coagulation. factors and platelets, rather than a rise as hoped. In 18 experimental perfusions in which ${ }^{125} \mathrm{I}-\mathrm{labelled}$ fibrinogen was used as a marker there was in every instance a significant loss of the fibrinogen into the fluid supporting the liver in the perfusion chamber. Further, in 11 of the perfusions there was an additional loss into liver substance, this being associated with a very rapid fall in ${ }^{125} I$ fibrinogen and platelets content of the perfusing fluid. Damage to the sinusoids from ischaemic damage incurred during removal of the liver could explain both the direct loss of fibrinogen and, as a result of intravascular coagulation, the associated loss within the perfused liver. No correlation could be found with biochemical function, but it proved possible to assess haematological safety before connexion of the patient to the perfusion by a shortened ${ }^{125}$ I fibrinogen test. This was done in three patients treated by five perfusions and in none was the thrombocytopenia or coagulation disturbance adversely affected.

\section{Introduction}

It is only 10 years since Eiseman et al. (1961) suggested using an isolated animal liver for the treatment of patients with hepatic failure. The liver most commonly used has been that of the pig (Eiseman, 1966; Norman et al., 1966; Watts et al., 1967; Abouna et al., 1969; Ranek et al., 1971), although calf (Condon and Bombeck, 1970; Battersby et al., 1971), monkey (Abouna et al., 1970, 1972), and cadaver human (Sen et al., 1966; Abouna et al., 1970) livers have been used. Such treatment has often resulted in the patient recovering from coma, even in a dramatic fashion, but the overall results from a number of centres have been poor. While this is partly a reflection of the severity of fulminant hepatic failure many deaths have been due to bleeding which has followed the perfusion. In some instances (Abouna et al., 1969, 1970) correction of haemostatic deficiencies in the patient has been attributed to the synthesis of coagulation factors by the perfused liver, but in most patients with bleeding this has been made worse rather than better. Parbhoo et al. (1971), in a report of six perfusions, concluded that it is a valuable form of therapy, though it is to be noted that two treatments were curtailed by haematomata in the patient; one patient died of widespread bleeding beginning after the first perfusion and increasing after the second, and one patient died of bleeding two hours after $\cdot$ a perfusion. The severe bleeding was associated with reduced platelet levels.

\footnotetext{
Liver Unit and Departments of Surgery and Morbid Anatomy,

King's College Hospital, London S.E.5

JOHN WINCH, F.R.C.S., F.R.A.C.S. Lecturer

J. KOLTHAMMER, Biochemist

R. HAGUE, B.SC., Biochemist

R. FLEISHER, M.B., CH.B., M.R.C.P., Registrar

K. B. SHILKIN, M.B., B.S., M.R.C.P.A., Lecturer

ROGER WILLIAMS, M.D., F.R.C.P., Director, Liver Research Unit
}

\author{
R. FLEISHER， K. B. SHILKIN， ROGER WILLIAMS
}

Nevertheless, at the moment this represents the most promising form of temporary liver support (Winch, 1971), and in this paper we report experimental studies on the mechanism of the coagulation disturbance, with its relation to biochemical function of the perfused liver. A test to determine haematological safety was developed and its value shown in five perfusions carried out in treatment of three patients in hepatic coma, none of these leading to significant worsening of the thrombocytopenia or coagulation disturbance.

\section{Technique for Extracorporeal Perfusion}

The liver was obtained under aseptic conditions from a pig previously anaesthetized through an endotracheal tube. To minimize ischaemic damage the liver was cooled to $7^{\circ} \mathrm{C}$ by perfusion of fluid through the portal vein. The cooling solution used, which also served to flush out the pig blood, was similar in ionic concentration and heparin content to that described by Abouna (1968), except that dextran and trometamol were replaced by Rheomacrodex and a phosphate buffer respectively. The liver was then floated in a bath of saline within the perfusion chamber of a closed circuit (Winch, 1971) which allowed delivery of heparinized, oxygenated, fresh human blood to the portal vein as a smooth gravity flow from a height of $15 \mathrm{~cm}$ and to the hepatic artery under a pulsatile pressure of $90 \mathrm{~mm} \mathrm{Hg}$ systolic. Rewarming to $38^{\circ} \mathrm{C}$ was performed slowly over 30 minutes. In the experimental studies bile salts necessary for the secretion of bile were provided by infusion of sodium taurocholate into the circulating blood at a constant rate of $12 \mu \mathrm{Eq} /$ min. Fluid exuding from the liver surface and cut hilar lymphatics ("ascites") passed direct into the surrounding saline, the volume of which was kept constant by the use of an overflow cannula from the chamber to the circuit. During clinical use this overflow was collected separately. The patient was connected to the circuit by means of two cannulae (Plexitron U511, Travenol) introduced into the vena cava through one or both long saphenous veins. These cannulae passed in opposite directions across a double-headed roller pump controlled at a speed independent of the flow in the liver circuit. Thus flows to and from the patient were about equal $(250-400 \mathrm{ml} / \mathrm{min}$ contributing to a total liver flow of $800-900 \mathrm{ml} / \mathrm{min}$ ), but any small inequality found by frequent monitoring of the patient's weight (facilitated by the use of a weighing bed), blood pressure, and central venous pressure, together with observation of levels of blood in the circuit reservoirs, was corrected by temporary clamping of the cannula leading to or from the patient.

\section{Experimental Studies on Coagulation}

In preliminary experiments we found that recirculation of fresh heparinized blood through the circuit without a liver in the perfusion chamber caused little if any lowering of platelet levels. This was not so, however, when the liver was in the circuit, and in 18 such studies there was a fall in the platelet count of $25-75 \%$ of the initial level after two hours of perfusion. The reduction in the platelet count was not correlated with the warm or cold ischaemia times or the duration of rewarming.

In these 18 studies we also attempted to determine quantitatively whether there was a loss of coagulation factors as well as of platelets. At the beginning of each study $10 \mu \mathrm{Ci}$ of ${ }^{125} \mathrm{I}$ 
fibrinogen was introduced into the perfusing blood and its subsequent rate of disappearance determined by serial sampling. The counts recorded in each sample included those due to free iodine and fibrinogen breakdown products in addition to those of the labelled fibrinogen. To determine the latter, the sample was recounted after the addition of thrombin, calcium, and protamine and removal of the resulting "thrombus"; the difference between the two counts giving that due to the fibrinogen, including small amounts of large molecular weight fibrin/fibrinogen degradation products. Serial samples of saline from the perfusion chamber were also counted, and since the volumes of the perfusate and saline were known the absolute amount of ${ }^{125} \mathrm{I}$ fibrinogen in perfusate or in saline and ascites could be determined at any time.

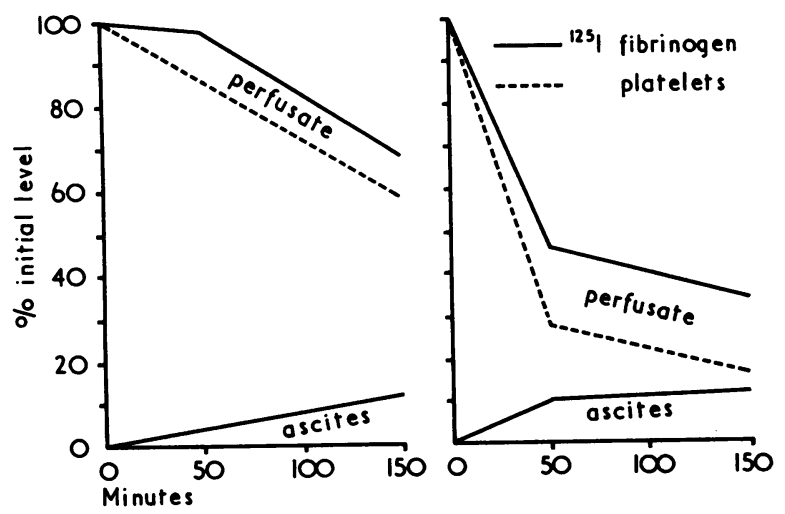

FIG. 1-125I fibrinogen and platelet disappearance from perfusing fluid in two perfusions of experimental series-illustrating slow fall in one and a more rapid fall in the other, which was attributed to an additional loss within the liver.

The results showed that the loss of ${ }^{125}$ I fibrinogen from the perfusate was similar to the rate of decrease in circulating platelets over the four hours of perfusion (Fig. 1). Labelled fibrinogen was detected in the ascites in all 18 studies, and in seven of these this accounted for almost all the fibrinogen lost from the perfusate. In the other 11 studies the amount lost into ascites was similar but the total loss from perfusate was greater (Table I). This additional loss appeared to be in the liver for fibrin deposits were shown on microscopical examination within the sinusoids (Fig. 2), whereas they were less prominent in the seven perfusions in which the total loss of fibrinogen was less and accountable for by that appearing in the ascites. In those perfusions where fibrinogen was lost into liver as well as into ascites the measured rate of ${ }^{125}$ I fibrinogen disappearance from the perfusate during the first hour was more rapid $\left(t \frac{1}{2}<120\right.$ $\mathrm{min}$ ) than in the other seven perfusions ( $t \frac{1}{2}>120 \mathrm{~min}$ ).

\section{RELATION TO BIOCHEMICAL FUNCTION}

Although the rate of bile flow during each experiment remained fairly constant there was considerable variation between each perfusion, with volumes of $10-80 \mathrm{ml}$ of bile produced during the four-hour period. Despite this variation the clearance of a load of $0.5 \mathrm{~g}$ of ammonium citrate from the perfusate was uniformly rapid, removal being complete within 60 minutes of administra-

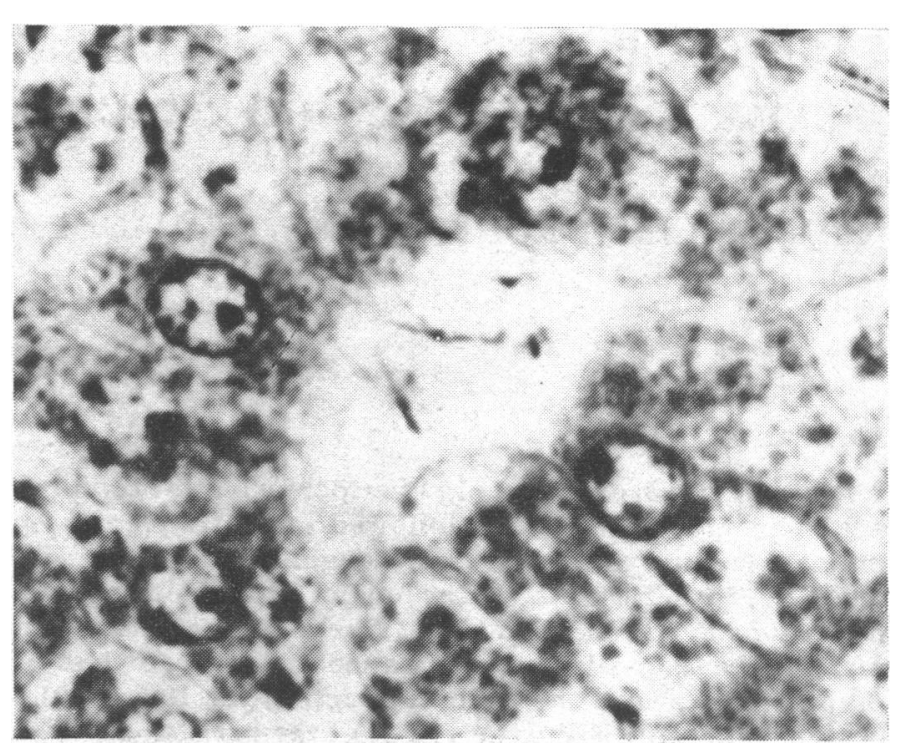

FIG. 2-Section of liver after four hours' perfusion showing several fine fibrin strands within a sinusoid. (Phosphotungstic acid-haematoxylin. $\times 750$, enlarged $\times 1.5$.)

tion. The clearance of bromsulphthalein was much slower, and it varied considerably with as much as $90 \%$ of the loading dose of $150 \mathrm{mg}$, or as little as $10 \%$, remaining in the perfusate at the end of 100 minutes. Even in those perfusions in which $90 \%$ of the bromsulphthalein was removed a significant amount remained in the liver, the percentage appearing in the bile being $75 \%$ or less.

Excretion of bromsulphthalein into bile was significantly correlated ( $r=0.89$ ) with the volume of bile secreted (Fig. 3 ) but no correlation could be detected between any of these measures of liver function and the warm or cold ischaemia times. The two groups of perfusions, divided according to the $t \frac{1}{2}$ for ${ }^{125 I}$

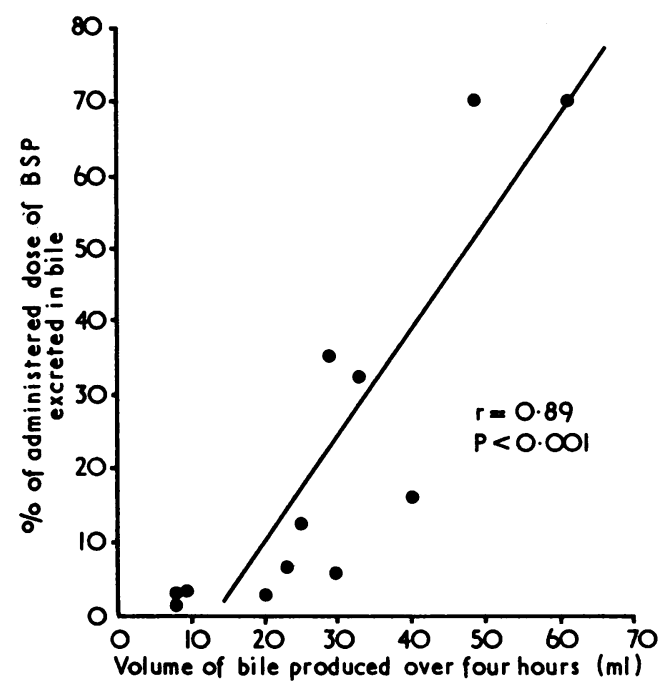

FIG. 3-Percentage of administered bromsulphthalein (BSP) excreted in bile related to total bile volume during four hours of perfusion. (Correlation obtained by method of Bravais-Pearson.)

rable I-Experimental Perfusions Divided into Two Groups According/ to Tt Fibrinogen Found

\begin{tabular}{|c|c|c|c|c|c|c|}
\hline \multirow{2}{*}{$\begin{array}{l}\text { 120IFibrinogen } \\
\text { t } 1 \text { in Perfusate } \\
\text { (min) }\end{array}$} & \multirow{2}{*}{$\begin{array}{l}\text { No. of } \\
\text { Studies }\end{array}$} & \multicolumn{2}{|c|}{$\begin{array}{c}\text { Ischaemic time } \\
\text { (Mean in min S.D.) }\end{array}$} & \multicolumn{2}{|c|}{$\begin{array}{c}\text { IaI Fibrinogen } \\
\text { (Mean \% } \pm \text { S.E. of Mean) }\end{array}$} & \multirow{2}{*}{$\begin{array}{c}\text { Bile Volume } \\
\text { in Four Hours } \\
\text { (Mean in } \mathrm{ml} \pm \text { S.E.M.) }\end{array}$} \\
\hline & & Warm & Cold & In Ascites & In Liver* & \\
\hline $\begin{array}{l}\geqslant 120 \\
<120\end{array}$ & ${ }_{11}^{7}$ & $\begin{array}{l}2 \cdot 7 \pm 0.5 \\
4 \cdot 1 \pm 2 \cdot 1 \\
\text { N.S. }\end{array}$ & $\begin{array}{l}68 \cdot 8 \pm 22 \cdot 0 \\
70 \cdot 4 \pm 29 \cdot 1 \\
\text { N.S. }\end{array}$ & $\begin{array}{l}8 \cdot 9 \pm 1 \cdot 3 \\
11 \cdot 1 \pm 2 \cdot 9 \\
\text { N.S. }\end{array}$ & $\begin{array}{l}8.0 \pm \pm 2.6 \\
36.8 \\
P<0.0 .8 \\
0.001\end{array}$ & $\begin{array}{l}29 \cdot 4 \pm 6 \cdot 2 \\
34.7 \pm 6 \cdot 3 \\
\text { N.S. }\end{array}$ \\
\hline
\end{tabular}

* Obtained by subtraction of that found in ascites from the total amount lost from perfusate.

N.S. = Not gignificant. 
fibrinogen, were also examined for differences in bile volume, ammonia clearance, or elimination of bromsulphthalein but no significant correlations were found.

\section{Results}

The first 30 minutes after rewarming the liver in the perfusion circuit was spent in ensuring that biochemical function was adequate and that the liver was haematologically safe. Only if the bile flow was more than $5 \mathrm{ml} / \mathrm{hr}$ and the $\mathrm{t}_{2} \frac{1}{2}$ of ${ }^{125} \mathrm{I}$ fibrinogen in perfusate 100 minutes or more was the patient connected. For the latter test in order to obtain the result rapidly we used ${ }^{125}$ I fibrinogen that had been purified by passage through an Amberlite resin column so that its free iodine content was low. The clearance curve of the labelled fibrinogen and calculated $t \frac{1}{2}$ is then very similar to that for the total ${ }^{125}$ I activity, which means that the result can be obtained within 5-10 minutes of taking the last sample, 20 minutes after rewarming.

Since these criteria were established we have used pig liver perfusion on five occasions in the treatment of three patients. All patients were in deep hepatic coma with greatly raised serum bilirubin levels and a severe coagulation disturbance. The perfusion was carried out only when full supportive therapy had failed to effect an improvement.

Case 1.-Male, 18 years. Subacute hepatic necrosis of four months' duration. Confused on admission deteriorating to grade 4 hepatic coma (as defined by Trey and Davidson, 1970) after a haematemesis. Perfusion decided on in order to allow time to find a donor organ for transplantation. Two perfusions were completed on the 13th and 15th days after admission. Both resulted in a fall of serum bilirubin and an improvement in electroencephalogram and conscious level, but neither had any effect on his profuse gastrointestinal haemorrhage, which finally caused his death 36 hours after the second perfusion. Necropsy showed hepatic necrosis with some regeneration nodules.

Case 2.-Male, 13 years. Fulminant hepatic failure from presumed viral hepatitis. Admitted on fifth day of illness in coma with decerebrate rigidity and pronounced opisthotonos. Blood sugar $15 \mathrm{mg} / 100 \mathrm{ml}$ on arrival, but no improvement when this was corrected. Perfusion began on day after admission. Despite blood pressure of only $50 \mathrm{~mm} \mathrm{Hg}$ at the start of perfusion a flow of $400 \mathrm{ml} / \mathrm{min}$ was obtained between patient and circuit. There was no noticeable change in grade of coma during perfusion, neither was there any bleeding. Perfusion was terminated by cardiac arrest. Necropsy showed massive hepatic necrosis without regeneration.

Case 3.-Female, 24 years. Fulminant hepatic failure after overdose of tranylcypromine and trifluoperazine dihydrochloride. Admitted in grade 4 hepatic coma. First perfusion on the following day improved conscious level to obeying spoken commands. but deterioration supervened with noticeable respiratory alkalosis and tetany. Second perfusion on the fifth day had little effect on conscious state and she died three days later. Necropsy showed massive hepatic necrosis without regeneration.

In none of these five perfusions did the patient's platelet count fall significantly (Table II) and haemorrhage was a problem only in Case 1, a patient who was bleeding profusely from the gastrointestinal tract before perfusion. In only one instance was the prothrombin time improved although the serum bilirubin was lowered in each perfusion, and the depth of coma was reduced in Case 3. The lack of improvement in conscious level in Case 2 may perhaps be explained by damage to the brain from the earlier episode of profound hypoglycaemia.

\section{Discussion}

The loss of fibrinogen to the fluid surrounding the pig liver during perfusion has not been reported previously and could represent a significant hazard for the patient, particularly if other coagulation factors are lost to the same extent. The radioactive fibrinogen studies also showed an additional site of loss in nearly two-thirds of the perfusions-namely, in the pig's liver. The most likely cause for the latter is intravascular coagulation developing as a consequence of ischaemic damage to the liver. The fibrin seen in the sinusoids of the liver at the end of perfusion is evidence of its occurrence. Such a process would also explain the parallel loss of platelets seen, by incorporation into the fibrin thrombi and adherence to damaged sinusoidal endothelium. Hutchinson et al. (1968) reported both in dogs and man a significant fall in blood platelets immediately on revascularization of the liver after transplantation and showed that it was not necessary to invoke an immane process, for the same occurred in dogs when the liver was made temporarily ischaemic in situ. On electron microscopy passage of platelets across a damaged sinusoidal endothelium was also seen.

The direct diffusion of the administered fibrinogen from perfusing fluid to surface is probably also a secondary effect of ischaemic damage to the sinusoidal wall incurred during preparation of the liver for perfusion. There was no correlation in our series between the extent of the fibrinogen loss, either into ascites or within the liver, and the warm or cold ischaemia times but there is other evidence pointing to hepatocyte damage. For instance, Strebel et al. (1969) showed that the isolated perfused liver has a lower maximal excretory rate for bromsulphthalein than the normal animal and in the present studies we found considerably less bromsulphthalein excreted into bile than was removed from the perfusate.

The occurrence of intravascular coagulation in the perfused liver may make perfusion more difficult, but the main adverse consequence is consumption of the circulating coagulation factors. Radioactive fibrinogen and other coagulation studies in patients with fulminant hepatic failure indicate that the haemorrhagic diathesis is, in addition to impairment of hepatic synthesis, due to the development of disseminated intravascular coagulation, presumably initiated by necrosis of liver cells and release of tissue thromboplastins (Rake et al., 1970, 1971). If such patients are exposed by pig liver perfusion to a further site of intravascular coagulation it is not surprising that bleeding so frequently ensues. Our results also showed that an adequate secretion of bile, or other measures of liver function, was no guarantee of satisfactory haematological function. The ${ }^{12} \mathrm{I} I$ fibrinogen test, however, does give a good indication and can easily be carried out before the perfused liver is connected to a patient.

The rapid clearance of circulating ammonia by the perfused livers, even by those secreting little bile, was of interest. Although a raised blood ammonia is only one of the metabolic abnormalities in hepatic coma this rapid clearance may explain why lightening of coma is the most frequent beneficial effect of extracorporeal perfusion. Lowering of serum bilirubin is also readily obtained but as part of this reduction is due to loss of

\begin{tabular}{|c|c|c|c|c|c|c|c|c|c|}
\hline \multirow{2}{*}{ Perfusion } & \multirow{2}{*}{$\underset{\text { (min) }}{\text { Duration }}$} & \multirow{2}{*}{$\begin{array}{l}\text { Total Blood } \\
\text { Flow, Patient } \\
\text { to Liver } \\
\text { (1.) }\end{array}$} & \multirow{2}{*}{$\begin{array}{l}\text { Bile Volume } \\
\text { During } \\
\text { Perfusion } \\
\text { (ml) }\end{array}$} & \multicolumn{2}{|c|}{$\underset{(\mathbf{m g} / \mathbf{1 0 0} \mathrm{ml})}{\text { Serum Bilirubin }}$} & \multicolumn{2}{|c|}{$\begin{array}{l}\text { Blood Platelets } \\
\mathrm{mm}^{2}\end{array}$} & \multicolumn{2}{|c|}{$\underset{\text { (sec prolonged) }}{\text { Prothrombin Time }}$} \\
\hline & & & & Before & After & Before & After & Before & After \\
\hline $\begin{array}{ll}\text { Case } 1 & \left\{\begin{array}{l}1 \mathrm{st} \\
2 \mathrm{nd}\end{array}\right. \\
\text { Case } 2 & \text { 1st } \\
\text { Case } 3 & \left\{\begin{array}{l}1 \mathrm{st} \\
2 \mathrm{nd}\end{array}\right.\end{array}$ & $\begin{array}{r}50 \\
92 \\
100 \\
110 \\
95\end{array}$ & $\begin{array}{l}12.5 \\
23.0 \\
40.0 \\
38.5 \\
28.5\end{array}$ & $\begin{array}{r}33 \\
12 \\
5 \\
20 \\
15\end{array}$ & $\begin{array}{l}27 \\
21 \\
24 \cdot 5 \\
21 \\
39 \cdot 5\end{array}$ & $\begin{array}{l}21 \\
15 \\
14 \\
18 \\
25\end{array}$ & $\begin{array}{r}87,000 \\
33,000 \\
30,000 \\
200,000 \\
30,000\end{array}$ & $\begin{array}{r}65,000 \\
33,000 \\
30,000 \\
198,000 \\
25,000\end{array}$ & $\begin{array}{r}4 \\
71 \\
23 \\
23 \\
16\end{array}$ & $\frac{6}{10}$ \\
\hline
\end{tabular}


bilirubin from the surface of the liver it is important that the ascites is not returned to the circuit during clinical perfusions. Benefit to the patient from the synthetic functions of the pig liver is likely to be small because of the limited time that perfusion is possible with human blood. Longer time is available with primate livers (either baboon or cadaver human), and Abouna et al. (1970) showed the potential of primate livers and indeed of the whole concept of extracorporeal perfusion in their report of survival of a patient with complete hepatic failure for two-and-a-half months using a total of 16 perfusions.

The lack of long-term survival in our patients is not surprising for all were treated at a very late stage of their diseace. It may well be that as with remal dialysis treatment will be more successful if carried out before serious metabolic complications have occurred. To do this, however, we must be sure that the liver placed in the extracorporeal circuit is safe haematologically as well as having adequate biochemical function. It is in this context that the ${ }^{125} \mathrm{I}$ fibrinogen test may prove to be of considerable help.

We wish to thank Dr. P. T. Flute and Dr. M. O. Rake for their help and advice, and Dr. R. A. Zeitlin and Dr. J. V. Barry, of the South London Transfusion Centre, for the supply of fresh human blood. This work was supported by a generous grant from the Wates Foundation.

\section{References}

Abouna, G. M. (1968). British fournal of Surgery, 55, 761.

Abouna, G. M., Kirkley, J. R., Hull, C. J., Ashcroft, T., and Kerr, D. N. S.

(1969). Lancet, 1, 64. G. (1970). Lancet, 2, 391 .

Abouna, G. M., Fisher, L. McA., Still, W. J., and Hume, D. M. (1972). British Medical fournal, 1, 23.

Battersby, C., Winch, J., Balderson, G., Cranitch, B., and Burnett, W. (1971). Australian and New Zealand fournal of Surgery, 40, 302.

Condon, R. E., and Bombeck, C. T. (1970). Surgical Clinics of North America, 50, 257.

Eiseman, B. (1966). Annals of the Royal College of Surgeons of England, 38,

Eiseman, B., Knipe, R., McColl, R. A., and Orlof, M. J. (1961). Archives of Surgery, 83, 356

Hutchinson, D. E., et al. (1968). Archives of Surgery, 93, 27.

Norman, J. C., Savaris, C. A., Brown, M. E., and McDermott, W. V., jun. (1966). Surgery, 60, 179 .

Parbhoo, S. P., et al. (1971). Lancet, 1, 659.

Rake, M. O., Flute, P. T., Pannell, G., and Williams, R. (1970). Lancet, 1,

Rake, M. O., et al. (1971). Lancet, 2, 1215.

Ranek, L., et al. (1971). Scandinavian Journal of Gastroenterology, Suppl. No. 9 , p. 161.

Sen, P. K., et al. (1966). Surgery, 59, 774.

Strebei, H. H., et al. (1969). Langenbecks Archiv für kliniche Chirugie, 325, 1118.

Trey, C., and Davidson, C. S. (1970). In Progress in Liver Disease, ed. H. Popper and F. Schaffner, vol. 3, chap. 18, p. 282. London, Heinemann. Watts, J. McK., Douglas, M. C., Dudley, H. A. F., Gurr, F. W., and Owen, J. A. (1967). British Medical fournal, 2, 341.

Winch, J. (1971). British Medical fournal, 1, 216.

\title{
Effect of Vagotomy on Ascorbic Acid Nutrition in Patients. with Peptic Ulcer
}

\author{
J. A. E. MACDONALD, M. M. COHEN
}

British Medical fournal, 1972, 2, 738-740

\section{Summary}

In 33 patients undergoing surgery for peptic ulcer it was found that both the dietary and the leucocyte ascorbic acid levels fell below the accepted normal values. Although after vagotomy the dietary intake improved dramatically, this was accompanied by only a small rise in leucocyte ascorbic acid levels. Evidence has been presented that the reduction in gastric acid output after vagotomy might be responsible for this paradox.

\section{Introduction}

Patients suffering from peptic ulcer have consistently low blood ascorbic acid levels (Archer and Graham, 1936; Harris, Abbasy, Yudkin, and Kelly, 1936; Platt, 1936; Lazarus, 1937; Portnoy and Wilkinson, 1938). The leucocyte ascorbic acid is generally regarded as the most reliable index of ascorbic acid nutrition (Bartley, Krebs, and O'Brien, 1953), and this too has been shown to be lowered in patients suffering from gastroduodenal disorders, including peptic ulcer (Cohen, 1967). These patients may have a reduced dietary intake of ascorbic acid, and this probably explains their poor nutritional status (Cohen and Duncan, 1967). With the restoration of a normal diet after successful surgery for duodenal ulcer, one might expect a

Department of Surgery, Western Infirmary, Glasgow W1

J. A. E. MACDONALD, M.B., CH.B., F.R.C.S., Surgical Registrar

M. M. COHEN, M.B., CH.B., F.R.C.s., Surgical Registrar (Present address Department of Surgery, Vancouver General Hospital, Vancouver 9, Canada)

similar improvement in leucocyte ascorbic acid levels. A study of a small group of patients, however, has shown that while there may be an appreciable improvement in ascorbic acid nutrition after vagotomy, normal status is not achieved (Cohen and Duncan, 1967). The reason for this is not fully understood. Nutritional problems after vagotomy. are not uncommon (Cox, Bond, Podmore, and Rose, 1964) and impaired ascorbic acid nutrition could be the result of diminished absorption of the vitamin due to the therapeutic hypochlorhydria.

The present study was constructed to confirm the effect of vagotomy on ascorbic acid nutrition in a larger group of patients, and to determine whether a relation exists between gastric acid output and the leucocyte ascorbic acid level after vagotomy.

\section{Methods}

Of the 40 patients originally studied, seven defaulted from follow-up and have been excluded. The remainder $(27$ men and 6 women) were aged 18 to 68 years, mean 45 years (S.D. $\pm 11 \cdot 3$ ). All had long-standing symptoms and had been selected for surgery before inclusion in this survey.

The dietary ascorbic acid levels were estimated before and after surgery by means of a questionnaire based on the tables of McCance and Widdowson (1960). Results were expressed as $\mathrm{mg} /$ day. Leucocyte ascorbic acid levels were estimated by the method of Denson and Bowers (1961). Fractionation of the cells and plasma was carried out within a few minutes of collection to minimize the uptake of ascorbic acid by the cells from the plasma. Though this method in fact measures the ascorbic acid content of the buffy layer, which contains both leucocytes and platelets, the results are conventionally expressed as $\mu \mathrm{g} / 10^{8}$ W.B.C. When the white count or platelet count is abnormal a correction factor is necessary (Gibson, Moore, and 